\title{
Escherichia coli Endotoxin Depresses Left Ventricular Contractility in Neonatal Lambs
}

\author{
GUSTAVO SOSA, JAY M. MILSTEIN, AND STEPHEN H. BENNETT
}

Division of Neonatology, Department of Pediatrics, University of California, Davis, Davis, California 95616

\begin{abstract}
We evaluated the effects of Escherichia coli endotoxin on the peripheral vascular hemodynamics and myocardial function of the newborn lamb to understand how gram-negative endotoxemia can lead to cardiovascular collapse in newborn infants. Fifteen lambs, $0-3 \mathrm{~d}$ old, were acutely instrumented with a micromanometer-tipped catheter and two pairs of ultrasonic crystals to measure left ventricular (LV) pressure and $L V$ anterior-posterior and septal-free wall dimensions, a fluid-filled catheter for monitoring aortic pressure, and an electromagnetic flow probe to measure systemic blood flow. Cardiovascular performance was evaluated by measuring or deriving the following variables: mean arterial blood pressure (MABP), LV pressure, heart rate, stroke volume, systemic vascular resistance, $L V$ dp/dt, end-diastolic area, arterial elastance, and end-systolic elastance (the slope of the end-systolic pressure-area relationship) as an index of contractility independent of loading conditions and heart rate. Once instrumented, nine lambs received endotoxin, $0.5 \mathrm{mg} / \mathrm{kg}$ i.v., and six animals, serving as controls, received a saline infusion. Of the endotoxin-treated lambs, five survived the duration of the study (120 min from the beginning of the endotoxin infusion), and four died by $90 \mathrm{~min}$ from the beginning of the endotoxin infusion. No significant changes in any of the cardiovascular variables occurred in the control group. A significant decrease in MABP was seen in all endotoxintreated animals by $45 \mathrm{~min}$ after the beginning of the endotoxin infusion. MABP decreased by $52 \%$ from baseline in the survivors and $38 \%$ in the nonsurvivors. In the survivors, the MABP stabilized with saline boluses, whereas in the nonsurvivors MABP continued to decrease until death. In the survivors, end-systolic elastance remained stable, and, despite changes in afterload, $\mathrm{LV} \mathrm{dp/dt}$ also remained stable throughout the study. In the nonsurvivors, the end-systolic elastance and $L V$ dp/dt exhibited a progressive decline until death, with the changes in the end-systolic elastance preceding the changes in $\mathrm{LV} \mathrm{dp} / \mathrm{dt}$. End-diastolic area and stroke volume remained stable during the study in both groups of endotoxin-treated animals, decreasing in the nonsurvivors just before death. Because the changes in end-systolic elastance and LV dp/dt clearly preceded the decreases in end-diastolic area and stroke volume in the nonsurvivors, we conclude that the myocardial depression in the nonsurvivors was primarily due to depressed myocardial contractility, not decreased preload. (Pediatr Res 35: 62-67, 1994)
\end{abstract}

\section{Abbreviations}

Ees, end-systolic elastance

LV, left ventricular

MABP, mean arterial blood pressure

Received May 26, 1993; accepted September 3, 1993.

Correspondence: Jay M. Milstein, M.D., Division of Neonatology, Department of Pediatrics, TB 193, University of California, Davis, Davis, CA 95616.
Infection in the human infant remains a major cause of mortality (1-3). This type of death is usually characterized by cardiovascular collapse. The cardiovascular changes that occur in both adult human beings and animal models in response to endotoxin have been studied extensively (4-7). However, limited information is available on the cardiovascular responses in the septic newborn. Because the newborn heart may be structurally and functionally immature and may be already functioning near maximum $(8,9)$ and because both systemic and pulmonary vascular resistances are undergoing such dramatic changes at birth, the newborn's response to endotoxin may be particularly critical. Understanding these changes may provide insight into the physiologic responses observed in the newborn, which may have significant implications regarding therapeutic strategies in critically ill infants. Few studies of experimental animal models have attempted to quantitate the cardiovascular changes that occur in the newborn (10-13), and none specifically have addressed the effects of endotoxic shock on the newborn's myocardial function using an index of contractility independent of loading conditions and heart rate. Therefore, the purpose of this study was to evaluate the effects of Escherichia coli endotoxin on peripheral vascular hemodynamics and myocardial function, with the use of Ees (the slope of the end-systolic pressure-area relationship) in a newborn ovine model of sepsis.

\section{MATERIALS AND METHODS}

Experimental preparation. Fifteen newborn lambs between 0 and $3 \mathrm{~d}$ of age with a mean weight of $4.18 \mathrm{~kg}$ (range $3.0-5.7 \mathrm{~kg}$ ) were blindfolded for calming and anesthetized with i.v. $\alpha$-chloralose $(50 \mathrm{mg} / \mathrm{kg}$ in sodium borate solution) via femoral venous catheters. Additional doses of $\alpha$-chloralose $(15-30 \mathrm{mg} / \mathrm{kg}$ ) were given as needed to maintain surgical anesthesia. Fluid-filled femoral arterial catheters were placed and attached to Medex pressure transducers (Hilliard, $\mathrm{OH}$ ) for arterial pressure measurement. After endotracheal intubation, the animals were placed on mechanical ventilation (Baby Bird Respirator, Palm Springs, CA). Arterial blood samples were analyzed using a blood gas analyzer (Radiometer, Copenhagen, Denmark). Gases were monitored every $30 \mathrm{~min}$ and maintained in physiologic ranges [pH 7.35 to 7.45; $\mathrm{PaCO}_{2} 4.39$ to $6.26 \mathrm{kPa}$ (33 to 47 torr); and $\mathrm{PaO}_{2} 13.06$ to $33.325 \mathrm{kPa}$ (98 to 250 torr)] by adjusting the ventilator and fractional inspired oxygen concentration and by administering sodium bicarbonate. The lambs' body temperatures were maintained at $39-40^{\circ} \mathrm{C}$ with external heating. Maintenance i.v. fluid with $D_{s} L R$ at approximately $100 \mathrm{~mL} / \mathrm{kg} /$ day, yielding a glucose infusion rate of approximately $3.5 \mathrm{mg} / \mathrm{kg} /$ min, was provided to prevent dehydration and hypoglycemia throughout the preparation and study period. After a left thoracotomy at the third intercostal space was performed, the pericardium was opened across the base along the course of the main pulmonary artery to expose the great vessels and ductus arteriosus. The ductus arteriosus was ligated. A $1-\mathrm{cm}$ segment of the 
descending aorta just cephalad to the hemizygous vein was dissected for placement of a cuffed vascular occluder. The animals were given lidocaine, $1 \mathrm{mg} / \mathrm{kg}$ i.v., for arrhythmia prophylaxis, and after gentle manual compression of the heart to reduce filling, the apex of the heart was popped out of the pericardial sac.

A midventricular short axis plane was visualized approximately half the distance from the apex to the base. The interventricular grooves were identified, and the free wall was visually divided into thirds. A pair of 4-mm hemispheric ultrasonic piezoelectric crystals (14) were then aligned in the area of the anterior and posterior thirds to measure the anterior-posterior dimension with a sonomicrometer (Triton Technology, San Diego, CA). These crystals were sewn to their respective epicardial surfaces. With a plastic sleeve as an introducer, a $2.5-\mathrm{mm}$ cylindrical crystal was tunneled into the interventricular septum along the same minor axis plane, along a 19-gauge needle tract placed to the left of the interventricular groove and below the juncture of the left anterior descending coronary artery and the first major diagonal branch. The fourth hemispheric crystal was then aligned along the lateral third of the free wall of the left ventricle to measure the septal-free wall dimension. After the animals were given an additional dose of lidocaine $(1 \mathrm{mg} / \mathrm{kg})$, the heart was gently compressed and replaced in the pericardial sac.

An electromagnetic flow probe (C \& C, Culver City, CA) was placed around the ascending aorta, which had been previously dissected free of the main pulmonary artery to measure LV output (minus coronary flow). This probe was connected to a Statham 2202 flowmeter (Gould Instruments, Oxnard, CA). A micromanometer-tipped catheter (Camino 420, San Diego, CA) was placed directly into the left ventricle through a 22 -gauge needle tract through the opening in the pericardial sac at the base. Placement of this catheter was verified by the presence of an LV wave form monitored on a Gould Recorder 2800S (Cleveland, $\mathrm{OH}$ ). Pharmacologic vagotomy was achieved by isolating the vagus trunks at the neck and irrigating them with $2 \%$ lidocaine. We ascertained that the pharmacologic vagotomy was adequate if no reflex bradycardia occurred during afterload manipulations used to generate transient increases in afterload described below.

All animal experimentation was performed with the highest standards of humane care in accord with the NIH Guide for the Care and Use of Laboratory Animals.

Data acquisition and experimental protocol. Once the instrumentation was completed, the animals were allowed to recover for approximately $30 \mathrm{~min}$. $E$. coli endotoxin (lipopolysaccharide E. coli 055:B5, List Biological Laboratories, Campbell, CA) in a dose of $0.5 \mathrm{mg} / \mathrm{kg}$ i.v. was given by constant infusion in $50 \mathrm{~mL}$ of normal saline over a $30-\mathrm{min}$ period. Nine lambs received endotoxin and six animals served as controls. The controls had the instrumentation and recordings conducted in the same manner, but $50 \mathrm{~mL}$ of normal saline alone was infused over a 30 min period. Hypotension developed in all lambs given endotoxin. They were given $20 \mathrm{ml} / \mathrm{kg}$ boluses of normal saline in response. None of the control animals received such boluses.

The following cardiovascular signals were recorded on a stripchart recorder (Gould 2800S, Cleveland, $\mathrm{OH}$ ): arterial blood pressure, systemic blood flow, LV pressure, anterior-posterior diameter, and septal-free wall diameter. Over a period of $2 \mathrm{~h}$ beginning before, during, and after the 30-min infusion, 20-s episodes of these signals were digitized at $200 \mathrm{~Hz}$ [National Instruments Lab-NB (Austin, TX) in an Apple Macintosh II microcomputer] at 15 -min intervals. The waveforms were analyzed by programs developed using the Labview data-flow programming language (National Instruments) to evaluate MABP, mean systemic flow, peak LV pressure, heart rate, LV anteriorposterior dimension, LV septal-free dimension, LV minor axis area (product of the anterior-posterior and septal-free dimen- sions), $\mathrm{LV} \mathrm{dp} / \mathrm{dt}_{\max }, \mathrm{LV} \mathrm{dp} / \mathrm{dt}_{\min }$, systemic vascular resistance, arterial elastance, and Ees.

The LV dp/dt was derived from the LV digitized tracing using the derivative algorithm in Labview. The arterial elastance was evaluated by dividing the total peripheral resistance by the duration of one cardiac cycle. The Ees was assessed from four waveforms, one recorded during a baseline state and another three in which the afterload was transiently increased by brief aortic constrictions. The end-systolic points and end-systolic pressure-area regression were evaluated using the algorithm described by Alyono et al. (15) to determine the left upper corner.

Statistical methods. The assessment of whether differences existed between the control and endotoxin-treated animals (survivors and nonsurvivors) was based on a univariate repeated measures analysis of variance. When a significant difference was present, Student's Newman-Keuls test was performed to detect which groups were different. A $p$ value of $<0.05$ was considered statistically significant for all tests. The endotoxin survivors and nonsurvivors were compared at times ranging from 30 to 90 min, using a $t$ test with Bonferroni's correction to determine the times at which differences occurred. Each comparison was assessed at a $p<0.01$ level of significance to adjust for an overall family error rate not to exceed 0.05 (16).

\section{RESULTS}

Cardiovascular variables were measured in six control animals and nine endotoxin-treated animals over a period of $120 \mathrm{~min}$. Five of the endotoxin-treated animals survived, whereas four died within $90 \mathrm{~min}$ from the beginning of the endotoxin infusion. Rather than assume that the remaining unmeasured variables in the nonsurvivors were missing values in the experimental design, we performed the analysis assuming that the endotoxin nonsurvivors represented a different population of lambs from endotoxin survivors. Thus the univariate analysis of variance was performed on the basis of three categories of animals: control, endotoxin survivor, and endotoxin nonsurvivor. No significant differences were noted between groups based on age or weight.

In the control group no significant differences were observed in any of the variables of cardiovascular function that we measured or derived throughout the course of the study, thus demonstrating that despite the extensive cardiothoracic surgical manipulation, this experimental preparation remains hemodynamically stable throughout the study period.

Before the beginning of the endotoxin infusion $(t=0)$, baseline measurements revealed no significant differences between most of the cardiovascular variables measured (Tables 1 and 2). However, resting heart rate and MABP were higher in the endotoxin survivors than in the endotoxin nonsurvivors.

In the endotoxin-treated animals a significant decrease occurred in MABP at $45 \mathrm{~min}$ from the beginning of the endotoxin infusion ( $15 \mathrm{~min}$ after infusion), with MABP decreasing by $52 \%$ in the endotoxin survivors and $38 \%$ in the endotoxin nonsurvivors as compared with baseline measurements (Fig. 1, Table 1). The MABP in the endotoxin survivors remained stable for the rest of the study. The MABP in the endotoxin nonsurvivors continued to decline at each observation period until death. All nonsurvivors died by $90 \mathrm{~min}$ after the endotoxin infusion was initiated (60 min after infusion).

In response to the hypotension, both endotoxin groups were treated with $20 \mathrm{~mL} / \mathrm{kg}$ boluses of normal saline at 45 and 60 min after the endotoxin infusion was initiated (15 and $30 \mathrm{~min}$ after infusion). These boluses did not have a detectable effect on MABP but may have maintained systemic flow and stroke volume. Because the control animals remained stable, no crystalloid boluses were given.

Systemic vascular resistance decreased significantly in both survivors and nonsurvivors compared with controls (Table 2); however, no statistical differences were found in the arterial 
Table 1. Hemodynamics*

\begin{tabular}{|c|c|c|c|c|c|c|c|c|c|}
\hline Variable & State & Baseline & $30 \mathrm{~min}$ & $45 \mathrm{~min}$ & $60 \mathrm{~min}$ & $75 \mathrm{~min}$ & $90 \mathrm{~min}$ & $105 \mathrm{~min}$ & $120 \mathrm{~min}$ \\
\hline $\mathrm{MABP}(\mathrm{mm} \mathrm{Hg}) \dagger$ & $\begin{array}{l}\text { Controls } \\
\text { Survivorsł } \\
\text { Nonsurvivors\$ }\end{array}$ & $\begin{array}{l}51 \pm 7.6 \\
60 \pm 14.7 \\
47 \pm 3.0\end{array}$ & $\begin{array}{l}46 \pm 5.3 \\
44 \pm 8.2 \\
50 \pm 10.1\end{array}$ & $\begin{array}{l}45 \pm 5.4 \\
31 \pm 6.1 \\
29 \pm 4.9\end{array}$ & $\begin{array}{l}44 \pm 4.3 \\
27 \pm 3.4 \\
27 \pm 3.7\end{array}$ & $\begin{array}{l}44 \pm 6.4 \\
30 \pm 5.4 \\
25 \pm 3.3\end{array}$ & $\begin{array}{l}46 \pm 7.0 \\
29 \pm 3.1 \\
21 \pm 1.8\end{array}$ & $\begin{array}{c}45 \pm 7.4 \\
31 \pm 9.0 \\
\text { N/A }\end{array}$ & $\begin{array}{c}46 \pm 7.4 \\
31 \pm 10.2 \\
\text { N/A }\end{array}$ \\
\hline $\begin{array}{l}\text { Stroke volume } \\
\quad(\mathrm{mL}) \dagger\end{array}$ & $\begin{array}{l}\text { Controls } \\
\text { Survivors }\end{array}$ & $\begin{array}{l}3.51 \pm 1.04 \\
3.42 \pm 0.76\end{array}$ & $\begin{array}{l}3.35 \pm 1.10 \\
3.21 \pm 1.07\end{array}$ & $\begin{array}{l}3.19 \pm 1.21 \\
3.86 \pm 1.62\end{array}$ & $\begin{array}{l}3.06 \pm 1.10 \\
3.36 \pm 1.68\end{array}$ & $\begin{array}{l}3.01 \pm 1.24 \\
3.39 \pm 0.57\end{array}$ & $\begin{array}{l}3.44 \pm 0.04 \\
3.07 \pm 0.48\end{array}$ & $\begin{array}{l}3.51 \pm 0.41 \\
3.67 \pm 0.40\end{array}$ & $\begin{array}{l}3.44 \pm 0.54 \\
3.36 \pm 0.14\end{array}$ \\
\hline & Nonsurvivors & $3.91 \pm 1.87$ & $4.0 \pm 1.85$ & $3.23 \pm 1.22$ & $3.69 \pm 2.74$ & $4.66 \pm 3.65$ & $1.43 \pm 0.15 \|$ & N/A & N/A \\
\hline $\begin{array}{l}\text { Cardiac output } \\
\text { (mL/min) }\end{array}$ & $\begin{array}{l}\text { Controls } \\
\text { Survivors } \\
\text { Nonsurvivors }\end{array}$ & $\begin{array}{l}630 \pm 283 \\
614 \pm 125 \\
610 \pm 237\end{array}$ & $\begin{array}{l}580 \pm 239 \\
568 \pm 158 \\
718 \pm 337\end{array}$ & $\begin{array}{l}556 \pm 243 \\
728 \pm 238 \\
603 \pm 251\end{array}$ & $\begin{array}{l}528 \pm 208 \\
662 \pm 142 \\
670 \pm 238\end{array}$ & $\begin{array}{l}547 \pm 235 \\
697 \pm 116 \\
832 \pm 626\end{array}$ & $\begin{array}{l}614 \pm 75 \\
608 \pm 50 \\
273 \pm 68\end{array}$ & $\begin{array}{c}607 \pm 74 \\
692 \pm 93 \\
\text { N/A }\end{array}$ & $\begin{array}{c}614 \pm 89 \\
607 \pm 73 \\
\text { N/A }\end{array}$ \\
\hline $\begin{array}{l}\text { Heart rate } \\
\text { (beats/min) } \dagger\end{array}$ & $\begin{array}{l}\text { Controls } \\
\text { Survivors } ¥ \\
\text { Nonsurvivorsf }\end{array}$ & $\begin{array}{l}178 \pm 39 \\
192 \pm 27 \\
161 \pm 15\end{array}$ & $\begin{array}{l}172 \pm 22 \\
186 \pm 22 \\
180 \pm 7\end{array}$ & $\begin{array}{l}173 \pm 17 \\
199 \pm 23 \\
185 \pm 9\end{array}$ & $\begin{array}{l}172 \pm 14 \\
205 \pm 15 \\
186 \pm 15\end{array}$ & $\begin{array}{l}181 \pm 14 \\
206 \pm 12 \\
185 \pm 19\end{array}$ & $\begin{array}{l}179 \pm 20 \\
203 \pm 17 \\
190 \pm 33\end{array}$ & $\begin{array}{c}173 \pm 16 \\
189 \pm 19 \\
\text { N/A }\end{array}$ & $\begin{array}{c}179 \pm 12 \\
181 \pm 15 \\
\text { N/A }\end{array}$ \\
\hline LVEDP $(\mathrm{mm} \mathrm{Hg}) \dagger$ & $\begin{array}{l}\text { Controls } \\
\text { Survivors } \\
\text { Nonsurvivors } \$ \S\end{array}$ & $\begin{array}{l}11.3 \pm 3.2 \\
15.9 \pm 4.6 \\
17.8 \pm 3.4\end{array}$ & $\begin{array}{l}15.3 \pm 4.2 \\
14.3 \pm 3.3 \\
17.9 \pm 10.1\end{array}$ & $\begin{array}{l}16.3 \pm 3.3 \\
13.0 \pm 2.4 \\
18.4 \pm 10.8\end{array}$ & $\begin{array}{l}15.3 \pm 4.2 \\
12.0 \pm 4.2 \\
15.3 \pm 8.2\end{array}$ & $\begin{array}{l}13.2 \pm 4.2 \\
17.0 \pm 8.3 \\
20.3 \pm 7.2\end{array}$ & $\begin{array}{l}14.8 \pm 3.1 \\
13.0 \pm 5.6 \\
16.0 \pm 1.2\end{array}$ & $\begin{array}{c}14.7 \pm 4.4 \\
13.6 \pm 2.0 \\
\text { N/A }\end{array}$ & $\begin{array}{c}15.9 \pm 3.4 \\
12.7 \pm 1.5 \\
\text { N/A }\end{array}$ \\
\hline $\begin{array}{l}\text { Systemic resistance } \\
(\mathrm{mm} \mathrm{Hg} / \mathrm{mL} / \mathrm{s}) \dagger\end{array}$ & $\begin{array}{l}\text { Controls } \\
\text { Survivors } \ddagger \\
\text { Nonsurvivors }\end{array}$ & $\begin{array}{l}5.6 \pm 2.1 \\
5.8 \pm 2.0 \\
5.2 \pm 1.8\end{array}$ & $\begin{array}{l}5.5 \pm 2.4 \\
5.3 \pm 2.1 \\
5.0 \pm 2.5\end{array}$ & $\begin{array}{l}5.8 \pm 2.8 \\
2.9 \pm 1.0 \\
3.3 \pm 1.6\end{array}$ & $\begin{array}{l}6.0 \pm 3.3 \\
3.0 \pm 1.2 \\
3.3 \pm 2.2\end{array}$ & $\begin{array}{l}6.5 \pm 4.9 \\
2.6 \pm 0.5 \\
2.6 \pm 1.6\end{array}$ & $\begin{array}{l}4.5 \pm 1.1 \\
2.9 \pm 0.5 \\
4.7 \pm 1.0\end{array}$ & $\begin{array}{c}4.5 \pm 1.1 \\
2.8 \pm 0.7 \\
\text { N/A }\end{array}$ & $\begin{array}{c}4.6 \pm 1.1 \\
3.0 \pm 0.6 \\
\text { N/A }\end{array}$ \\
\hline
\end{tabular}

- Normal saline or endotoxin are infused for the first $30 \mathrm{~min}$ for controls or survivors and nonsurvivors, respectively. All values are reported as mean \pm 1 SD. ANOVA, repeated measures analysis of variance; LVEDP, LV end-diastolic pressure; N/A, not available.

$\dagger p<0.05$ significant difference between group controls, survivors, and nonsurvivors according to analysis of variance.

$\ddagger p<0.05$ significant difference between group survivors and controls, multiple comparison Student's Newman-Keuls test.

$\S p<0.05$ significant difference between group nonsurvivors and controls, multiple comparison Student's Newman-Keuls test.

$\| p<0.01$ significant difference between groups at a given time, multiple comparison using $t$ test with Bonferroni correction.

I $p<0.05$ significant difference between group survivors and nonsurvivors, multiple comparison Student's Newman-Keuls test.

Table 2. Myocardial performance*

\begin{tabular}{|c|c|c|c|c|c|c|c|c|c|}
\hline Var & State & Baseline & $30 \mathrm{~min}$ & $45 \mathrm{~min}$ & $60 \mathrm{~min}$ & $75 \mathrm{~min}$ & $90 \mathrm{~min}$ & $105 \mathrm{~min}$ & $120 \mathrm{~min}$ \\
\hline $\begin{array}{l}\text { EDA } \\
\qquad\left(\mathrm{mm}^{2}\right) \dagger\end{array}$ & $\begin{array}{l}\text { Controls } \\
\text { Survivorsł } \\
\text { Nonsurvivors }\end{array}$ & $\begin{array}{l}8 \\
3 \\
30\end{array}$ & $\begin{array}{l}1 \\
5 \\
7\end{array}$ & $\begin{array}{l}7 \\
3 \\
5\end{array}$ & $\begin{array}{l}37 \\
6 \\
05\end{array}$ & $\begin{array}{l}38 \\
6 \\
28\end{array}$ & $\begin{array}{l}89 \\
56 \\
39\end{array}$ & $\begin{array}{c}456 \pm 105 \\
505 \pm 56 \\
\text { N/A }\end{array}$ & $\begin{array}{c}456 \pm 105 \\
501 \pm 35 \\
\text { N/A }\end{array}$ \\
\hline Ees & Controls & $0.78 \pm 0.26$ & $0.69 \pm 0.22$ & $0.62 \pm 0.31$ & $0.66 \pm 0.22$ & $0.68 \pm$ & $0.71 \pm 0.25$ & $0.70 \pm 0.28$ & $0.68 \pm 0.33$ \\
\hline (n & $\begin{array}{l}\text { Survivors } \\
\text { Nonsurvivors } \| \S\end{array}$ & & $\begin{array}{l}0.69 \pm 0.17 \\
0.54 \pm 0.14\end{array}$ & $\begin{array}{l}0.59 \pm 0.11 \\
0.42 \pm 0.13 \pi\end{array}$ & $\begin{array}{l}0.68 \pm 0.17 \\
0.42 \pm 0.03 \pi\end{array}$ & $\begin{array}{l}0.75 \pm 0.24 \\
0.26 \pm 0.159\end{array}$ & $\begin{array}{l}0.65 \pm 0.18 \\
0.16 \pm 0.09\end{array}$ & $\begin{array}{c}0.75 \pm 0.22 \\
\text { N/A }\end{array}$ & $\begin{array}{c}0.55 \pm 0.29 \\
\text { N/A }\end{array}$ \\
\hline $\begin{array}{r}\mathrm{LV} \mathrm{dp} / \mathrm{dt} \max \\
(\mathrm{mm} \mathrm{Hg} / \mathrm{s}) \dagger\end{array}$ & $\begin{array}{l}\text { Controls } \\
\text { Survivors } \\
\text { Nonsurvivors } § \S\end{array}$ & $\begin{array}{r}1249 \pm 490 \\
1239 \pm 314 \\
763 \pm 262\end{array}$ & $\begin{array}{r}1130 \pm 506 \\
1263 \pm 601 \\
933 \pm 318\end{array}$ & $\begin{array}{r}1096 \pm 518 \\
1110 \pm 112 \\
659 \pm 327\end{array}$ & $\begin{array}{r}1040 \pm 503 \\
872 \pm 313 \\
585 \pm 263\end{array}$ & $\begin{aligned} 1083 & \pm 407 \\
946 & \pm 436 \\
401 & \pm 193 \pi\end{aligned}$ & $\begin{array}{r}1068 \pm 417 \\
1062 \pm 461 \\
186 \pm 989\end{array}$ & $\begin{array}{r}982 \pm 396 \\
1061 \pm 499 \\
\text { N/A }\end{array}$ & $\begin{array}{c}995 \pm 324 \\
826 \pm 484 \\
\text { N/A }\end{array}$ \\
\hline
\end{tabular}

* Normal saline or endotoxin are infused for the first $30 \mathrm{~min}$ for controls or survivors and nonsurvivors, respectively. All values are reported as mean \pm 1 SD. ANOVA, repeated measures analysis of variance; EDA, end-diastolic area; N/A, not available.

$\dagger p<0.05$ significant difference between group controls, survivors, and nonsurvivors according to analysis of variance.

$\ddagger p<0.05$ significant difference between group survivors and controls, multiple comparison Student's Newman-Keuls test.

$\S p<0.05$ significant difference between group nonsurvivors and controls, multiple comparison Student's Newman-Keuls test.

$\| p<0.05$ significant difference between group survivors and nonsurvivors, multiple comparison Student's Newman-Keuls test.

I $p<0.01$ significant difference between groups at a given time, multiple comparison using $t$ test with Bonferroni correction.

elastance between or within the groups for the duration of our study.

The end-diastolic area, an indicator of the preload state of the left ventricle, as well as the stroke volume and systemic flow, remained stable throughout the course of the study in both survivor and control groups with no statistically significant changes (Table 1). In the nonsurvivor group, end-diastolic area, stroke volume, and systemic flow also remained stable until 90 min, just before death, when they decreased significantly (Table 1).

LV dp/dt did not change significantly in the endotoxin survivors. In the endotoxin nonsurvivors, $\mathrm{LV} \mathrm{dp/dt} \mathrm{showed} \mathrm{a} \mathrm{decreas-}$ ing trend at $15 \mathrm{~min}$ after infusion, reaching statistical significance at $45 \mathrm{~min}$ after endotoxin infusion. This decline continued at each observation period until death (Fig. 2, Table 2).

No statistically significant change occurred in the Ees during the course of the study in the controls and in the endotoxin survivors. However, a statistically significant decrease occurred in the Ees of the nonsurvivors beginning at $30 \mathrm{~min}$ after endotoxin infusion as compared with the survivors. For this group, the Ees continued to decrease steadily throughout the study (Figs.
3 and 4 , Table 2). Before the nonsurvivors' deaths, the Ees was only $28 \%$ of its mean baseline value.

\section{DISCUSSION}

Septic shock is a major cause of death in newborn infants. In our animal model, the dose of $E$. coli endotoxin used was lethal in $44 \%$ of our animals over the duration of the study. The major difference between the nonsurvivors and survivors was a decrease in contractility in the former group.

During the course of the experiment, we observed a decrease in blood pressure in all endotoxin-treated animals. Volume was given at 15 and $30 \mathrm{~min}$ after endotoxin infusion to preserve stroke volume and systemic flow to prevent ischemia as the basis for myocardial dysfunction. No improvement in MABP was detected in response to the volume. However, in the survivors the blood pressure stabilized after the initial decline, but in the nonsurvivors it continued to decline until death, $60 \mathrm{~min}$ after infusion.

Subsequent analysis revealed that, despite a decrease in MABP in the survivors, $\mathrm{LV} \mathrm{dp} / \mathrm{dt}$ and Ees remained unchanged through- 


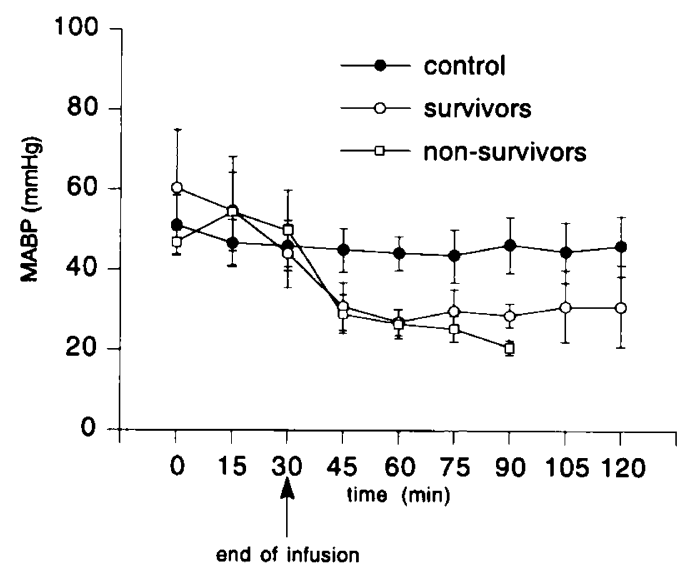

Fig. 1. MABP in response to either an endotoxin or saline infusion [controls $(\Theta)$, survivors $(O)$, and nonsurvivors $(\square)$ ] at baseline $(t=0), 30$ (end of infusion), 45, 60, 90, 105, and $120 \mathrm{~min}$. Values expressed are mean $\pm 1 \mathrm{SD}$.

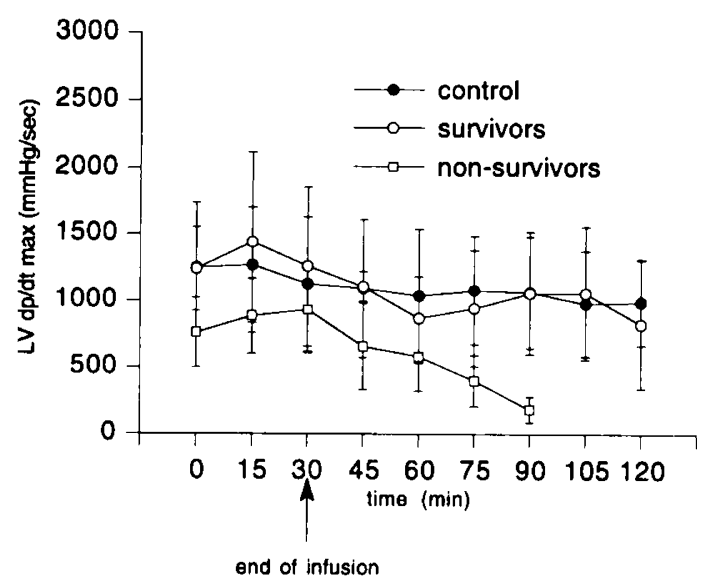

Fig. 2. LV dp/dt max in response to either an endotoxin or saline infusion [controls $(\Theta)$, survivors $(O)$, and nonsurvivors $(\square)$ ] at baseline $(t$ $=0$ ), 30 (end of infusion), 45, 60,90, 105, and $120 \mathrm{~min}$. Values expressed are mean $\pm 1 \mathrm{SD}$.

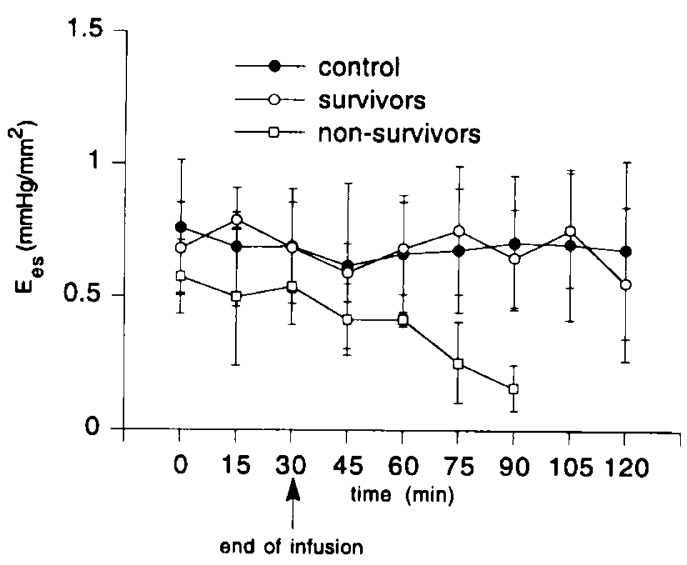

Fig. 3. Ees in response to either an endotoxin or saline infusion [controls $(\Theta)$, survivors $(O)$, and nonsurvivors $(\square)$ ] at baseline $(t=0), 30$ (end of infusion), 45, 60, 90, 105, and $120 \mathrm{~min}$. Values expressed are mean $\pm 1 \mathrm{SD}$.

out the study period. Stroke volume, systemic flow, and enddiastolic area also remained stable. LV dp/dt did not change despite the initial changes in afterload, as shown by a decrease in blood pressure and systemic resistance. In the surviving lambs, the initial decrease in afterload (MABP and systemic resistance) in the presence of stable myocardial contractility may have been beneficial. This decrease could allow them to maintain stroke volume and systemic flow, which in turn prevented global ischemic effects because the stroke volume in the neonate is highly dependent on afterload (17). The preload may have been preserved by the volume given based on a stable LV end-diastolic pressure and end-diastolic area.

In contrast, the nonsurvivors exhibited a progressive decline in MABP, LV dp/dt, and Ees until death occurred. In the nonsurvivors the volume given did not stabilize the blood pressure as it had in the survivors, and it did not prevent the progressive decrease in contractility. However, the volume given in the face of the potentially favorable decrease in afterload may have preserved stroke volume, systemic flow, and end-diastolic area, all of which remained stable until just before death. The volume of normal saline given $(20 \mathrm{~mL} / \mathrm{kg})$ has been administered in 1-, 2-3, and 4-wk old lambs and shown not tr generate significant changes in contractility compared with baseline; however, it did increase left atrial pressure (18), and, presumably, LV preload and output. Because we did not measure coronary blood flow or its distribution, we cannot definitively address the issue of global ischemia as the basis of myocardial dysfunction. However, in global ischemia, LV compliance decreases. Such compliance changes would be manifested by increases in end-diastolic, anterior-posterior, and septal-free dimensions; end-diastolic area; and a leftward shift of the diastolic relationship between LV pressure and minor axis area (19). These manifestations were not present in our nonsurvivors. Therefore global ischemia leading to myocardial dysfunction is an unlikely explanation for the persistent depression in contractility in the nonsurvivors.

In sepsis and endotoxemia, an increase in pulmonary vascular resistance occurs $(20,21)$ that can cause right to left shunting across fetal channels, as well as intrapulmonary shunting resulting in hypoxemia, which may depress the myocardium. In this study, the ductus arteriosus was ligated, and the $\mathrm{PaO}_{2}$ was maintained by manipulating the $\mathrm{FIO}_{2}$, ruling out hypoxemia as the cause for myocardial depression in the nonsurviving animals. In addition, Milstein et al. (22) demonstrated that, in acutely anesthetized neonatal lambs, acute hypoxia results in an increase in both LV dp/dt and systemic blood flow, probably resulting from catecholamine release. The lack of these observations in our study provides further support against hypoxemia as the basis for dysfunction in our nonsurvivors.

An increase in pulmonary vascular resistance can also increase right ventricular afterload and mechanically alter LV performance by direct ventricular interaction. Because end-diastolic area and systemic flow did not change significantly, which may have been influenced by the boluses given, a decrease in preload or a decrease in filling is unlikely to account for the decrease in myocardial performance in the nonsurvivors. As previously shown by Milstein and Glantz (23), this mechanical right ventricular-LV interaction in newborn lambs affects $L V$ filling (decreases end-diastolic area) but does not affect contractility. Therefore we conclude that other factors, such as the endotoxin itself or a mediator (activated or released), as proposed by Parker and Adams (24), affected myocardial function. Nitric oxide may be such a mediator, In endotoxemia, nitric oxide production within cardiac myocytes has been shown to reduce their contractility (25), whereas its release from arteriolar endothelium results in vasodilation (26).

The change in LV dp/dt in nonsurvivors is difficult to interpret because of the sensitivity of this index to loading conditions, inotropic state, and heart rate. The change in $\mathrm{LV} \mathrm{dp} / \mathrm{dt}$ seemed to follow the decline in blood pressure and was preceded by a decrease in the Ees; therefore the change could be explained on the basis of decreasing afterload, decreasing contractility, or both. Because the specificity of the index LV dp/dt for contractility is limited, we calculated the Ees as an index of myocardial contractility independent of loading conditions and heart rate (27- 

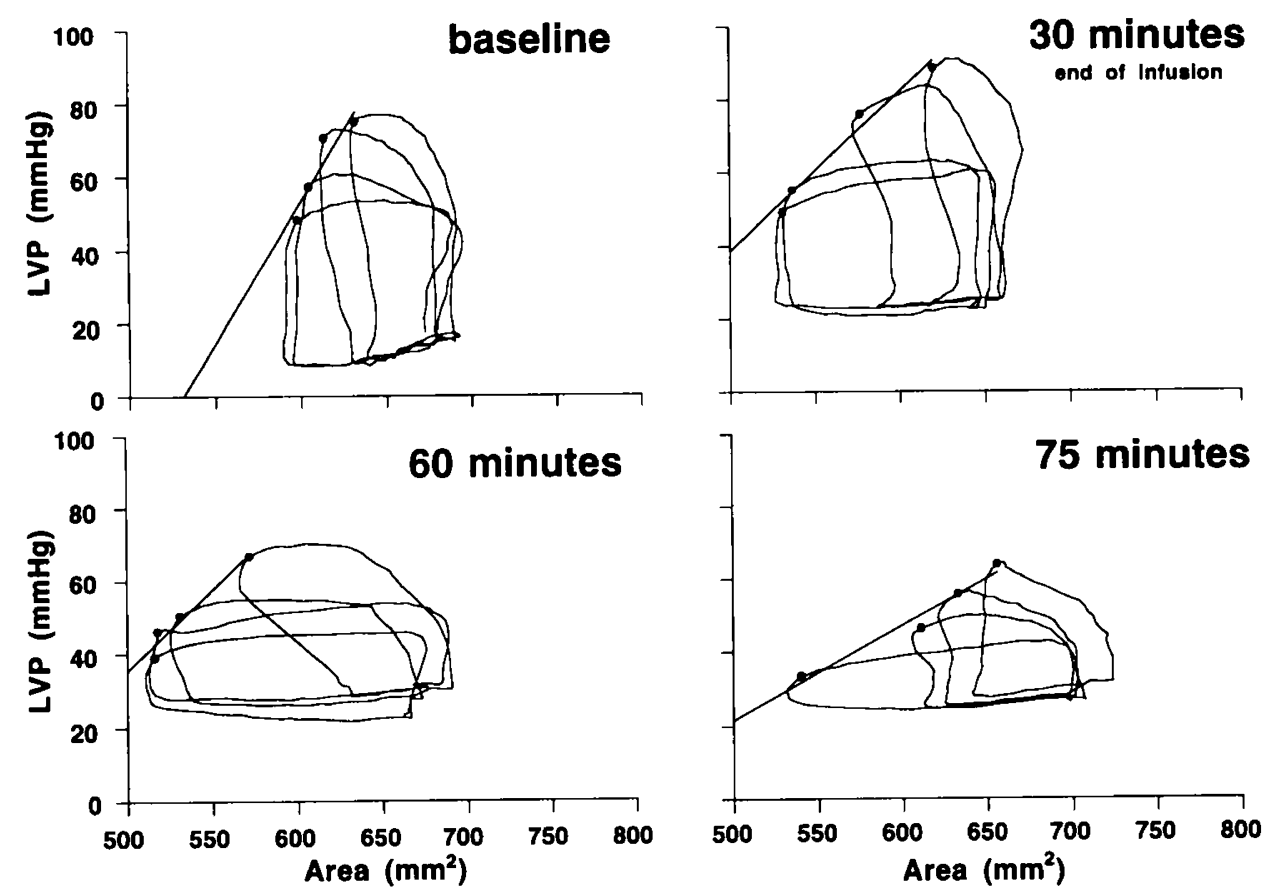

Fig. 4. LV pressure-area loops used to derive the Ees at baseline, 30 (end of infusion), 60, and $75 \mathrm{~min}$ in a nonsurvivor. The Ees decreases steadily over the course of the study.

30). Sagawa (27) has shown that Ees does depend on the subject's body size and that good correlation with ventricular function and contractile state exists, providing the ventricles compared are of similar size. The ventricles in our lambs were of comparable size. Teitel et al. (31), using pressure-volume loops, determined the reliability and reproducibility of the Ees in newborn lambs. Teitel $e t$ al. (18) had previously shown that single-dimension measurements can be substituted for volume estimates providing the ventricles are of similar size. However, this technique may have some limitations. Milstein and Glantz (23) used the Ees in newborn lambs using pressure-area loops, which were also used as estimates of the pressure-volume relationship in this study. Because the newborn minor axis plane is not perfectly circular and the relative anterior-posterior and septal-free wall movements may be asymmetric in the first few days of life, two minor axis dimensions in the same plane were selected. In addition, according to Appleyard and Glantz (32) the area of the minor axis plane may be more highly correlated with volume than individual minor axis dimensions.

A paucity of reports in the literature exists regarding the neonatal response to endotoxin, and none clearly distinguishes the peripheral vascular and myocardial contributions to the circulatory effects $(11-13)$. Using noninvasive pulsed Doppler in neonatal piglets exposed to endotoxin between 5-29 d, Lobe et al. (13) identified an increase in cardiac output and cardiac index data in an early phase, which we did not observe, and a decrease in a later phase, which we may have masked with the supplemental normal saline boluses. In our study, systemic vascular resistance decreased early and remained low, whereas in the piglets, systemic vascular resistance decreased in the early phase and increased in the later phase. Key differences exist between the study by Lobe et al. and our findings. First, their piglets were older and some of the early and potentially more critical transitional circulatory changes may have already occurred in the 0 to 3-d period. Second, to lump 5- to 29-d-old piglets may obscure later age-specific differences because both developmental and physiologic changes continue during the first month of life (18). In another study by Goto et al. (12), 2- to 10-d-old and 11- to 20-d-old dogs were exposed to endotoxin. Systemic blood pressures decreased after $60 \mathrm{~min}$ in their low-dose exposure to lipopolysaccharide $(1.5 \mathrm{mg} / \mathrm{kg})$, which is similar to our findings.
In contrast to our findings, cardiac output decreased within 5 $\mathrm{min}$ to this exposure. With the larger dose of $10 \mathrm{mg} / \mathrm{kg}$ lipopolysaccharide, both blood pressure and cardiac output decreased very rapidly. A key difference between their work and ours, which limit their comparability, is that the doses of lipopolysaccharide are 3 and 20 times greater than the dose we used. Finally, it is not possible to clearly separate the vascular and myocardial contributions to the changes observed in either of the studies cited.

Reports in the literature differ regarding when myocardial function deteriorates during endotoxic shock and its relationship to cardiovascular collapse. Our findings differ from those of Kober et al. (33), who infused a lethal dose of endotoxin into an anesthetized adult dog model and found that myocardial depression occurred late and only during the agonal phase. Guntheroth et al. (34) found early and sustained depression of myocardial function in their adult dog model of endotoxic shock. The anesthesia used was pentobarbital, which theoretically may have affected contractility. Goldfarb et al. (35), using an adult canine model of endotoxemia, found, similar to us, that survivors had no significant change in their contractility but that in nonsurvivors contractile function and MABP exhibited a progressive decline until death occurred. Therefore despite structural and functional differences with age, similar global cardiovascular responses were present in our newborn model as some adult models.

The basis for the profoundly different responses to endotoxin in our nonsurvivors and survivors certainly may warrant some speculation, particularly if such speculation could permit earlier recognition of an "at risk" status in a clinical setting. It has been suggested that prior exposure to bacterial antigens may alter subsequent responses to endotoxin (11). In our series, all lambs were delivered vaginally in farm settings, potentially increasing exposure to environmental antigens compared with those delivered by hysterotomy. However, because none appeared clinically ill before study, differentiation of the two groups on this basis was not possible. Examination of the baseline hemodynamic measurements may be more helpful. At baseline, the nonsurvivors had significantly lower resting heart rates and MABPs than the survivors. In addition, although no significant differences in myocardial contractility existed, as measured by Ees or, in LV 
$\mathrm{dp} / \mathrm{dt}_{\max }$, between the nonsurvivors and survivors, there was a trend for them to be lower. These differences do suggest that the nonsurvivors may have had less $\beta$-adrenergic tone or less myocardial $\beta$-adrenoreceptor concentration and activity and thus relatively lower indices of ventricular function and less reserves to respond to endotoxin. Normally, within the first week of life, lambs have been shown to be in a high $\beta$-adrenergic state. Consequently, their hearts are already approaching maximum contractility. In contrast, by $1 \mathrm{mo}$, their $\beta$-adrenergic state is lower, but because their $\beta$-adrenoreceptor concentration is the same as at $1 \mathrm{wk}$, their cardiac reserve is greater but they still only attain the same level of maximum contractility as at $1 \mathrm{wk}$ when stimulated with isoproterenol (18). We are speculating that our nonsurviving lambs are not similar to the normal 1 -mo-olds with lower $\beta$-adrenergic tone because their lower adrenergic states have a pathologic or developmental, not physiologic basis. This explanation is in sharp contrast to that proposed by Goldfarb et al. (35) but consistent with developmental differences between neonates and adults. Goldfarb et al. (35) had postulated that the nonsurvivors had a higher basal sympathetic tone (higher MABP, Ees, and heart rate) before the infusion of endotoxin and therefore less cardiac reserve than survivors.

In summary, endotoxin caused myocardial depression in some but not all of our experimental animals. Those animals in which contractility was affected did not survive. Whether intervention with inotropic support to improve contractility at the onset of a decrease in Ees would improve the outcome in this model of neonatal sepsis was not evaluated but may be clinically important. Finally, establishing whether another index of contractility that would be more readily accessible clinically would permit more timely intervention to block or reverse the progression of myocardial dysfunction would be valuable.

Acknowledgment. The authors thank Michael H. Feren for his technical assistance.

\section{REFERENCES}

1. Harris MC, Polin RA 1983 Neonatal septicemia. Pediatr Clin North Am $30: 243-258$

2. Siegel JD, McCracken GH 1981 Sepsis neonatorum. N Engl J Med 304:642647

3. Daum RS, Smith AL 1979 Bacterial sepsis in the newborn. Clin Obstet Gynecol 22:385-408

4. Zeller WP, Goto M, Hurley RM 1988 Endotoxin in newborn septic shock: significance, metabolic, and cardiovascular changes. Ann Clin Lab Sci 18:253-259

5. Suffredini AF, Fromm RE, Parker MM, Brenner M, Kovacs JA, Wesley RA, Parrillo JE 1989 The cardiovascular response of normal humans to the administration of endotoxin. N Engl J Med 321:280-287

6. NIH Conference 1990 Septic shock in humans, advances in the understanding of pathogenesis, cardiovascular dysfunction, and therapy. Ann Intern Med 11 3:227-242

7. Abel FL 1989 Myocardial function in sepsis and endotoxin shock. Am J Physiol 257:R1265-R1281

8. Riemenschneider TA, Brenner RA, Mason DT 1981 Maturational changes in myocardial contractile state of newborn lambs. Pediatr Res 15:349-356
9. Friedman WF 1972 The intrinsic physiologic properties of the developing heart. Prog Cardiovasc Dis 15:87-111

10. Reddin JL, Boleslaw S, Spink WW 1965 Comparative hemodynamic and humoral responses of puppies and adult dogs to endotoxin. Am J Physiol 210:540-544

11. O'Brien WF, Golden SM, Davis SE, Bibro MC 1985 Endotoxemia in the neonatal lamb. Am J Obstet Gynecol 151:671-674

12. Goto M, Griffin AJ, Chiemmongkoltip P, Onouchi Z, Bernheim B 1988 Endotoxin shock in newborn dogs: serial hemodynamic studies. J Lab Clin Med 112:109-117

13. Lobe TE, Woodall DL, Griffin MP 1991 Early hemodynamic indicators of gram-negative sepsis and shock in an infant pig model. J Pediatr Surg 26:1051-1057

14. Van Trigt P, Bauer BJ, Olsen CO, Wechsler AS 1981 An improved transducer for measurement of cardiac dimensions and sonomicrometry. Am J Physiol 240:H664-H668

15. Alyono D, Larson VE, Anderson RW 1985 Defining end systole for endsystolic pressure ratio. J Surg Res 39:344-350

16. Glantz SA, Slinker BK 1990 Primer of Applied Regression and Analysis of Variance. McGraw-Hill, New York, p 294

17. Van Hare GF, Hawkins JA, Schmidt KG, Rudolph AM 1990 The effects of increasing mean arterial pressure on left ventricular output in newborn lambs. Circ Res 67:78-83

18. Teitel DF, Sidi D, Chin T, Brett C, Heymann MA, Rudolph AM 1985 Developmental changes in myocardial contractile reserve in the lamb. Pediatr Res 19:948-955

19. Visner MS, Arentzen CE, Parrish DG, Larson EV, O'Connor MJ, Crumbley III AJ, Bache RJ, Anderson RW 1985 Effects of global ischemia on the diastolic properties of the left ventricle in the conscious dog. Circulation 71:610-619

20. Rojas J, Stahlman M 1984 The effects of group B streptococcus and other organisms on the pulmonary vasculature. Clin Perinatol 11:591-599

21. Pearl RG, Baer ER, Siegel LC, Benson GV, Rice SA 1992 Longitudinal distribution of pulmonary vascular resistance after endotoxin administration in sheep. Crit Care Med 20:119-125

22. Milstein JM, Bennett SH 1987 Increased right ventricular afterload alters left ventricular function in newborn lambs. Am Heart J 114:369-377

23. Milstein JM, Glantz SA 1993 Mechanically increased right ventricular after load alters left ventricular configuration, not contractility, in neonatal lambs. Pediatr Res 33:359-364

24. Parker JL, Adams HR 1979 Myocardial effects of endotoxin shock: catheterization of a heart muscle model. Adv Shock Res 2:163-175

25. Brady AJB, Poole-Wilson PA, Harding SE, Warren JB 1992 Nitric oxide production within cardiac myocytes reduces their contractility in endotoxemia. Am J Physiol 263:H1963-H1966

26. Baker CH, Sutton ET 1993 Arteriolar endothelium-dependent vasodilation occurs during endotoxin shock. Am J Physiol 264:H1118-H1123

27. Sagawa $K 1978$ The ventricular pressure-volume diagram revisited. Circ Res 43:677-687

28. Mahler F, Covell JW, Ross Jr J 1975 Systolic pressure-diameter relations in the normal conscious dog. Cardiovasc Res 9:447-455

29. Gilson M, Crozatier B, Laplace M 1989 Left ventricular pressure-diameter relations in the conscious rabbit. Cardiovasc Res 23:7-15

30. Goldfarb RD, Lee KJ, Andrejuk T, Dziuban SW 1990 End-systolic elastance as an evaluation of myocardial function in shock. Circ Shock 30:15-26

31. Teitel DF, Klautz R, Steendijk P, Van Der Velve ET, Van Bel F. Baan J 1991 The end-systolic pressure volume relationship in the newborn lamb: effects of loading and inotropic interventions. Pediatr Res 29:473-482

32. Appleyard RF, Glantz SA 1990 Two dimensions describe left ventricular volume change during hemodynamic transients. Am J Physiol 258:H277H284

33. Kober PM, Thomas JX, Raymond RM 1985 Increased myocardial contractility during endotoxin shock in dogs. Am J Physiol 249:H715-H722

34. Guntheroth WG, Jacky JP, Kawabori I, Stevenson JG. Moreno AH 1982 Left ventricular performance in endotoxin shock dogs. Am J Physiol 242:H172ventric

35. Goldfarb RD, Tambolini W, Wiener SM, Weber PB 1983 Canine left ventricular performance during LDS0 endotoxemia. Am J Physiol 244: $\mathrm{H} 370-\mathrm{H} 377$ 